\title{
Cost Effectiveness of Romiplostim for the Treatment of Chronic Immune Thrombocytopenia in Ireland
}

\author{
Dawn Lee • Patrick Thornton • Alexander Hirst • \\ Lucie Kutikova $\cdot$ Robert Deuson · Nic Brereton
}

Published online: 16 July 2013

(c) The Author(s) 2013. This article is published with open access at Springerlink.com

\begin{abstract}
Background Romiplostim, a thrombopoietin receptor agonist (TPOra), is a second-line medical treatment option for adults with chronic immune thrombocytopenia (ITP). Clinical trials have shown that romiplostim increases platelet counts, while reducing the risk of bleeding and, in turn, the need for costly rescue medications.

Aims The objective of this study was to assess the cost effectiveness of romiplostim in the treatment of adult ITP in Ireland, in comparison with eltrombopag and the medical standard of care (SoC).

Methods A lifetime treatment-sequence cost-utility Markov model with embedded decision tree was developed from an Irish healthcare perspective to compare romiplostim with eltrombopag and SoC. The model was driven by platelet response (platelet count $\geq 50 \times 10^{9} / \mathrm{L}$ ), which determined effectiveness and progression along the treatment pathway, need for rescue therapy (e.g. intravenous
\end{abstract}

Electronic supplementary material The online version of this article (doi:10.1007/s40258-013-0044-y) contains supplementary material, which is available to authorized users.

D. Lee $(\square) \cdot$ A. Hirst $\cdot$ N. Brereton

BresMed, North Church House, 84 Queen Street,

Sheffield S1 2DW, UK

e-mail: dlee@bresmed.co.uk

P. Thornton

Beaumont Hospital, Beaumont, Dublin, Ireland

L. Kutikova

International Health Economics,

Amgen (Europe) GmbH, Zug, Switzerland

R. Deuson

Global Health Economics, Amgen Inc.,

Thousand Oaks, CA, USA immunoglobulin [IVIg] and steroids) and risk of bleeding. Probability of response, mean treatment duration, average time to initial response and utilities were derived from clinical trials and other published evidence. Treatment sequences and healthcare utilization practice were validated by Irish clinical experts. Costs were assessed in $€$ for 2011 and included drug acquisition costs and costs associated with monitoring patients and management of bleeding, as available from published Irish reimbursement lists and other relevant sources. Deterministic and probabilistic sensitivity analyses were conducted.

Results Romiplostim treatment resulted in an average of 20.2 fewer administrations of rescue medication (IVIg or intravenous steroids) over a patient lifetime than eltrombopag, and 29.3 fewer rescue medication administrations than SoC. Romiplostim was dominant, with cost savings of $€ 13,258$ and $€ 22,673$ and gains of 0.76 and 1.17 quality-adjusted life-years (QALYs), compared with eltrombopag and SoC, respectively. Romiplostim remained cost effective throughout a variety of potential scenarios, including short-term TPOra treatment duration (1 year). One-way sensitivity analysis showed that the model was most sensitive to variation in the cost of IVIg and use of romiplostim and IVIg. Probabilistic sensitivity analysis showed that romiplostim was likely to be cost effective in over $90 \%$ of cases compared with eltrombopag, and $96 \%$ compared with SoC at a willingness-to-pay threshold of $€ 30,000$ per QALY.

Conclusions Use of romiplostim in the ITP treatment pathway, compared with eltrombopag or SoC, is likely to be cost effective in Ireland. Romiplostim improves clinical outcomes by increasing platelet counts, reducing bleeding events and the use of IVIg and steroids, resulting in both cost savings and additional QALYs when compared with current treatment practices. 


\section{Key Points for Decision Makers}

- Results of the cost-effectiveness analysis showed that treatment with romiplostim was dominant, with cost savings compared with both eltrombopag and standard of care, including rituximab, whether given before or after rituximab in the Irish immune thrombocytopenia treatment pathway.

- Savings are achieved through higher response rates, driving a reduction in bleeding and the use of intravenous immunoglobulins and steroids.

\section{Introduction}

Primary immune thrombocytopenia (ITP; previously termed idiopathic thrombocytopenic purpura), an acquired immune-mediated disorder characterized by low peripheral blood platelet counts $\left(<100 \times 10^{9} / \mathrm{L}\right)$, is attributed to increased platelet destruction and suboptimal platelet production $[1,2]$. In adults, ITP is typically a chronic condition (>12 months), with spontaneous remissions relatively uncommon. A review of published literature, based mainly on Western European data, found that the annual incidence of ITP has been estimated at approximately 3-4 per 100,000 person-years in adults, while in children, estimates ranged from 1.9 to 6.6 per 100,000 person-years [3]. While precise epidemiology estimates for Ireland are lacking, an incidence of 3.9 per 100,000 person-years has been reported in the UK population-based General Practice Research Database [4].

Chronic ITP can have serious clinical and economic consequences, particularly linked to bleeding and impaired quality of life (QOL). While many patients may present with no symptoms or with minor bruising, others experience serious bleeding, including gastrointestinal bleeds, extensive skin and mucosal bleeds and/or intracranial haemorrhage [2]. Physical symptoms are a primary driver of diminished QOL, and ITP patients score poorly on QOL scales such as bother, psychological impact, fear, social activity and work [5]. The economic burden of chronic ITP has been examined in several studies [6]. An annual cost of $€ 26,581$ (year 2007 values) per hospitalized patient has been reported in France, with rescue medication accounting for a substantial proportion of costs [6]. In the USA, ITP drug therapy alone is estimated to account annually for hundreds of millions of dollars [7], with mean annual perpatient costs estimated at approximately $\$ \mathrm{US} 28,000$ (year 2000-2003 values) [8]. Studies that have examined the costs associated with ITP consistently reveal that adults with chronic ITP incur substantial per-patient medical costs, primarily due to hospitalization required to manage bleeding events, drug costs and costs of surgical intervention [6-9], as well as having lower work productivity [7].

Active treatment is recommended for adult ITP patients with platelet counts $<30 \times 10^{9} / \mathrm{L}$, or $30-50 \times 10^{9} / \mathrm{L}$ with bleeding or risk of bleeding $[1,2]$. First-line treatment typically consists of a short course of glucocorticoids, intravenous immunoglobulin G (IVIg) or anti-D (Rho) immunoglobulin (anti-D), all of which target platelet destruction [2]. These treatments generally provide relatively short-lived platelet responses, with many patients requiring repeated high doses of corticosteroids to maintain a safe platelet count, at the risk of undesirable adverse effects. Second-line options include surgical splenectomy and various treatments based on immune suppression, including off-label treatment with the anti-CD20 monoclonal antibody rituximab [2].

The thrombopoietin receptor agonists (TPOra) romiplostim and eltrombopag offer a different approach to treatment of ITP, by increasing platelet production [1,2]. In Europe, both TPOra are approved for use in splenectomized adult patients who are refractory to other treatments (e.g. corticosteroids, IVIg), and as second-line treatment for those who are not candidates for splenectomy $[10,11]$. As noted in an International Consensus Report, TPOra are the only ITP treatments with evidence of efficacy and safety from randomized controlled trials [2].

Health technology assessment is becoming increasingly required in the decision-making process in Ireland. We therefore conducted a cost-effectiveness analysis of romiplostim for the treatment of chronic ITP in adult patients in Ireland, from an Irish national payer perspective. In line with the guidelines for economic evaluation in Ireland [12], we considered only direct costs.

\section{Methods}

\subsection{Patient Population and Model Structure}

A treatment-sequence cost-utility model was developed to assess the cost effectiveness of romiplostim within its licensed indication for adult chronic ITP splenectomized patients who are refractory to other treatments (e.g. corticosteroids, IVIg), and as second-line treatment for adult non-splenectomized patients where surgery is contra-indicated. The patient cohort that was modelled had similar characteristics to patients from the romiplostim phase III trials [13] and individuals participating in an Irish survey [14]. A total of $50 \%$ of patients were assumed to be splenectomized and $50 \%$ non-splenectomized. The median age was 52 years, and $65 \%$ were women [13]. Three treatment strategies were compared (Fig. 1): 
Romiplostim

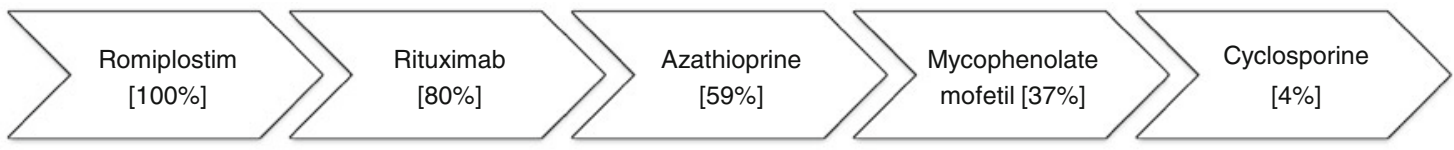

\section{Eltrombopag}

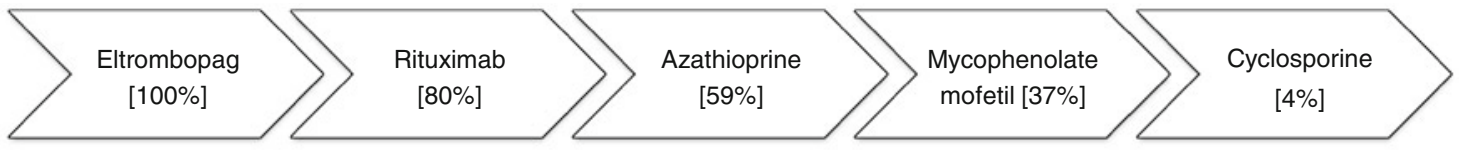

SOC including rituximab

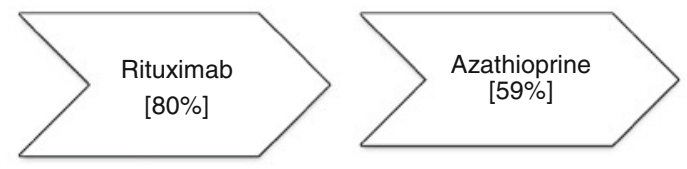

Fig. 1 Model treatment pathways for adult immune thrombocytopenia (the proportions of patients represent patient treatment flow after the failure of the previous treatment based on the findings of a 2008

- romiplostim followed by current medical standard of care $(\mathrm{SoC})$;

- eltrombopag followed by SoC;

- SoC, including rituximab.

As rituximab use in ITP is off-label, the base-case analyses assumed that TPOra were received before rituximab in this pathway. However, as some patients might receive romiplostim or eltrombopag after rituximab, this treatment pathway was tested in sensitivity analysis. After failing rituximab, patients moved on to azathioprine followed by mycophenolate mofetil and finally cyclosporine. The SoC pathway comprised rituximab ( $80 \%$ of patients), azathioprine $(59 \%)$, mycophenolate mofetil $(37 \%)$ and cyclosporine (4\%).

A Markov model with embedded decision tree was used with a 4-week cycle and a lifetime time horizon, developed from the perspective of the Irish national healthcare payer. A lifetime time horizon was deemed to be the most appropriate, since adult ITP tends to be a chronic disease; the 4-week cycle was used to match the evaluation schedule used in the long-term extension study [15]. Costs and outcomes were discounted at a $4 \%$ annual rate, as recommended by the Health Information and Quality Authority (HIQA) in Ireland [12]. The treatment sequence used in the model was based on the findings of a 2008 survey of 169 UK clinicians [16], and was updated by two Irish clinicians to be applicable for Ireland [17].

The model was driven by platelet response (platelet count $\geq 50 \times 10^{9} / \mathrm{L}$ ), which determined effectiveness and progression along the treatment pathway, need for rescue

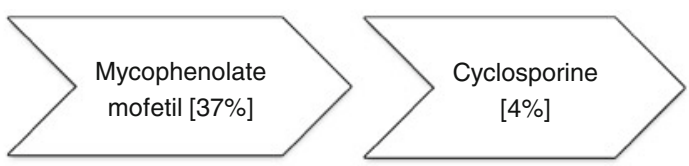

survey of 169 UK clinicians [16] updated and validated to match Irish practice [17]). SOC standard of care

therapy (IVIg and steroids) and risk of bleeding (Fig. 2). Patients started on the first treatment in the pathway and progressed to the next treatment if they did not have an initial response or if they relapsed (platelet count $<50 \times$ $10^{9} / \mathrm{L}$ ) after responding. Each relapse on active treatment, determined by platelet count $<50 \times 10^{9} / \mathrm{L}$, was followed by a period of 'watch and rescue' before initiating the next active treatment. Long-term treatment (keeping patients on active therapy for as long as they had a continued response) was modelled in the base case, and short-term treatment (1 year only) with romiplostim and eltrombopag was tested in a sensitivity analysis.

\subsection{Clinical Inputs}

Clinical efficacy data and utilities were derived from clinical trials, an International Consensus Report [2] and other published evidence.

The efficacy of each treatment within the model was characterized by three parameters (Table 1):

- probability of initial platelet response $\left(\geq 50 \times 10^{9} / \mathrm{L}\right)$;

- average time to initial response;

- treatment duration after initial response (treatment failure defined as platelets $<50 \times 10^{9} / \mathrm{L}$ for 4 consecutive weeks) [i.e. durability of response].

Efficacy data for romiplostim were taken from the pivotal phase III trials reported by Kuter et al. [13] and a subsequent long-term extension study [15]. The parallel, multicentre, double-blind, placebo-controlled phase III trials were conducted in splenectomized and non- 


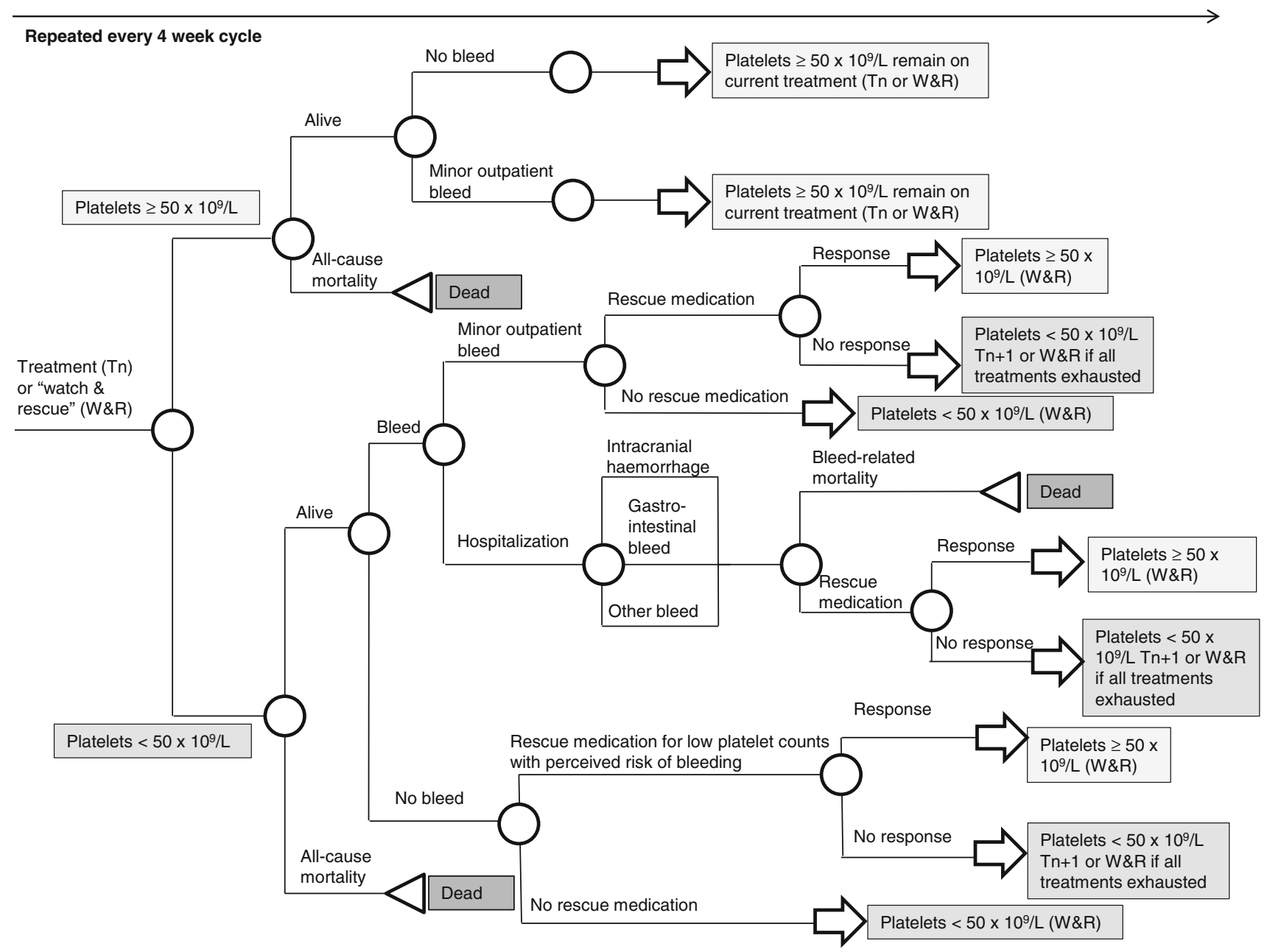

Fig. 2 Markov model with embedded decision tree overview (health states [platelets $\geq 50 \times 10^{9} / \mathrm{L}$, platelets $<50 \times 10^{9} / \mathrm{L}$, dead] evaluated in 4-week cycles). $G I$ gastrointestinal, $W \& R$ watch and rescue, $T n$ current treatment, $T n+1$ next treatment in sequence

splenectomized patients. Patients were randomized to receive romiplostim or placebo over a 24 -week period, with dosages adjusted according to weekly platelet counts.

In order to facilitate a comparison with eltrombopag, an odds ratio calculated by Bayesian meta-regression [18] was used to derive relative response rates for eltrombopag versus romiplostim (using romiplostim data from the clinical studies mentioned above) [13], as shown in Online Resource 1, Table 1A. The Bayesian meta-regression used a logit model to indirectly compare the two TPOra, accounting for differences in study effect, treatment effect and the effect of splenectomy. In a sensitivity analysis, use of the unadjusted response rate of $57 \%$ for eltrombopag [18] was also tested. The response rates for all other treatments were obtained from published literature (see Table 1). The time to response for each intervention was assumed to be equal to the maximum response time cited in the International Consensus Report (see Table 1) [2].
It was assumed that all patients who initiated therapy received treatment throughout this time-to-response period, with the exception of rituximab, which was given as a single course. Treatment duration (time to platelets $<50 \times$ $10^{9} / \mathrm{L}$ ) was modelled for all treatments by retrospectively fitting survival curves to available data. For romiplostim, this was based on the reported number of patients who were still on-treatment (or withdrew from the study for reasons other than treatment failure) at each 12-week interval in the 24-week trial and subsequent long-term, open-label, extension study (using data for up to 288 weeks and taking censoring into account) $[13,15]$. Weibull, logNormal, log-logistic, exponential and Gompertz survival curves were fitted to these data to allow extrapolation. The mean duration of romiplostim treatment was estimated by calculating the mean of the log-Normal function, which was the best-fitting curve according to the Akaike Information Criterion (AIC) (Table 2A, Figure 1A, Online Resource 1). A similar analysis was conducted for the 
Table 1 Clinical model inputs

\begin{tabular}{|c|c|c|c|}
\hline Treatment & $\begin{array}{l}\text { Probability } \\
\text { of response } \\
(\%)\end{array}$ & $\begin{array}{l}\text { Mean response } \\
\text { duration (cycles) }\end{array}$ & $\begin{array}{l}\text { Time to } \\
\text { initial } \\
\text { response } \\
\text { (cycles) }[2]\end{array}$ \\
\hline Romiplostim & 83 [13] & $140.86[15]$ & 1 \\
\hline $\begin{array}{l}\text { Eltrombopag- } \\
\text { adjusted } \\
\text { response rate }\end{array}$ & 35 [18] & 89.66 [19] & 1 \\
\hline $\begin{array}{l}\text { Eltrombopag- } \\
\text { unadjusted } \\
\text { response rate }\end{array}$ & 57 [18] & 89.66 [19] & 1 \\
\hline Rituximab & $58[39,40]$ & $18.87[41-43]$ & 2 \\
\hline Azathioprine & 56 [44-46] & 20.34 [47] & 6 \\
\hline $\begin{array}{l}\text { Mycophenolate } \\
\text { mofetil }\end{array}$ & $50[48-50]$ & $5.68[49]$ & 2 \\
\hline Cyclosporine & $57[45,51-53]$ & $14.54[53]$ & 1 \\
\hline IVIg & 81 [54-65] & $1[66]$ & 0 \\
\hline IV steroids & $46[57,67]$ & $1[66]$ & 0 \\
\hline
\end{tabular}

$I V$ intravenous, IVIg intravenous immunoglobin

mean treatment duration for eltrombopag, using the results of the ongoing EXTEND (eltrombopag extended dosing) study [19]. Based on the reported number of patients who were still on-treatment or who dropped out for reasons other than treatment failure, assuming a constant rate of patient dropout and taking censoring after 2 years into account, the log-Normal function was used to estimate the mean treatment duration [20]. Again, the log-Normal function was also the best-fitting curve based on the AIC (Table 2A, Figure 1A, Online Resource 1). For all other treatments, treatment duration was modelled by fitting exponential curves through any available data points from papers identified within the literature review that reported the proportion of patients still responding over time.

While adverse events play a significant role in the treatment of ITP, they were not included in the model due to limited evidence available on the rates of events and their impact on costs and QOL.

\subsubsection{Bleeding Events and Rescue Medication Use}

In the phase III romiplostim clinical trials, a proportion of non-responders (i.e. patients with a platelet count $<50 \times$ $\left.10^{9} / \mathrm{L}\right)$ received rescue medication. It is noteworthy that whilst a platelet count of $\geq 50 \times 10^{9} / \mathrm{L}$ was targeted in these trials, no clinically significant bleeding occurred when platelet counts were $>20 \times 10^{9} / \mathrm{L}$ [21]. The probability of experiencing bleeding was based on clinical trial data: patients who had a platelet count $\geq 50 \times 10^{9} / \mathrm{L}$ were assumed to have a $12.64 \%$ per-cycle probability of an outpatient bleed (i.e. not requiring hospitalization) and a $0.30 \%$ per-cycle probability of an inpatient bleed (requiring hospitalization) [21]. Corresponding per-cycle probabilities for patients with a platelet count $<50 \times 10^{9} / \mathrm{L}$ were calculated as 40.77 and $3.69 \%$, respectively [21]. Among patients with an inpatient bleed, it was assumed that $7 \%$ experienced intracranial haemorrhage, $21 \%$ experienced a gastrointestinal bleed and $71 \%$ experienced another type of bleed [21]. Similarly, for each cycle, it was assumed that $40 \%$ of patients with a platelet count $<50 \times 10^{9} / \mathrm{L}$ would receive IVIg, while $8 \%$ would receive intravenous corticosteroids, for treatment of inpatient or outpatient bleeding, or for bleeding prevention [21]. As anti-D is not available in Europe, all patients who received anti-D were assumed to receive IVIg (which has a similar response rate to that of anti-D) [2].

\subsubsection{Mortality}

The model included combined mortality resulting from serious bleeding and all-cause mortality. All-cause mortality for patients was based on Irish life tables [22]. The mortality risks associated with each type of bleed were based on an analysis of the American Nationwide Inpatient Sample (NIS) from 2003 to 2006 [9].

\subsubsection{Utility}

Utilities were taken from a time trade-off (TTO) survey [23] conducted in the UK. The survey used TTO analysis to directly measure the utility values for patients with ITP, as perceived by 359 members of the general public, and defined by five health states:

1. sufficient platelets $\left(\geq 50 \times 10^{9} / \mathrm{L}\right)$ with no outpatient bleed;

2. sufficient platelets with an outpatient bleed;

3. low platelets $\left(<50 \times 10^{9} / \mathrm{L}\right)$ with no outpatient bleed;

4. low platelets with an outpatient bleed;

5. intracranial haemorrhage.

An outpatient bleed refers to bleeding treated at a clinic, health centre or general practice. For the remaining health states used within the model (platelets $<50 \times 10^{9} / \mathrm{L}$ and gastrointestinal bleeding and platelets $<50 \times 10^{9} / \mathrm{L}$ and other bleeding), a utility value of 0.54 was used [24]. The utilities were derived from cardiovascular patients who experienced stroke, as ITP-specific data were not available. EQ-5D utility values were available from the phase III romiplostim clinical trials [13], with data from 117 patients pooled across placebo and romiplostim arms, under the conservative assumption that there is no treatment effect on utility [25]. The TTO utility values [23] were used in the base case (due to the larger sample size) and use of EQ-5D values $(n=117)$ was investigated in sensitivity analysis (Table 2). 
Table 2 Immune thrombocytopenia patient utilities

\begin{tabular}{lll}
\hline State & $\begin{array}{l}\text { Time-trade off } \\
\text { utilities [23] }\end{array}$ & $\begin{array}{l}\text { EQ-5D } \\
\text { utilities [25] }\end{array}$ \\
\hline Platelets $>50 \times 10^{9} / \mathrm{L}$ and no bleeding & 0.863 & 0.790 \\
Platelets $>50 \times 10^{9} / \mathrm{L}$ and bleeding managed in outpatient care & 0.734 & 0.730 \\
Platelets $<50 \times 10^{9} / \mathrm{L}$ and no bleeding & 0.841 & 0.840 \\
Platelets $<50 \times 10^{9} / \mathrm{L}$ and bleeding managed in outpatient care & 0.732 & 0.730 \\
Platelets $<50 \times 10^{9} / \mathrm{L}$ and intracranial haemorrhage & 0.038 & 0.038 \\
Platelets $<50 \times 10^{9} / \mathrm{L}$ and GI bleeding [24] & 0.540 & 0.540 \\
Platelets $<50 \times 10^{9} / \mathrm{L}$ and other bleeding [24] & 0.540 & 0.540 \\
\hline
\end{tabular}

GI gastrointestinal

\subsection{Costs and Resource Use}

Costs were assessed in $€$, year 2011 values, from the perspective of the Irish health service, exclusive of value added tax (VAT), as per HIQA guidelines [12]. The model considered drug acquisition and costs associated with monitoring patients and management of bleeding. Resource use and costs were derived from the International Consensus Report [2], published Irish reimbursement lists, individual summaries of product characteristics (SPCs) $[10,11]$, real-life observational data [26] and other relevant sources (Table 3). Healthcare utilization, such as frequency of physician and nurse visits, was validated by Irish clinicians [17]. The cost of bleeds was estimated by taking a weighted average of the relevant cost with and without complications. The base-case model assumed that patients received each treatment that they initiated for as long as they continued to respond, with the exception of rituximab, which was assumed to be given for a single course only. Where 2011 values were not available, costs were inflated using the health inflator derived from Central Statistics Office Ireland [12].

The cost of IVIg was assumed to be $€ 45$ per g based on Irish clinical practice [17] - this is lower than the list price

Table 3 Healthcare utilization and costs

\begin{tabular}{|c|c|c|c|c|c|c|}
\hline Treatment & Drug cost [27] & Dose [2] & $\begin{array}{l}\text { Physician } \\
\text { appointments } \\
\text { including tests } \\
(€ 160.60)[68-70]\end{array}$ & $\begin{array}{l}\text { Nurse } \\
\text { appointments } \\
(€ 9)[12]\end{array}$ & $\begin{array}{l}\text { IV admins } \\
(€ 300)[71]\end{array}$ & Total costs \\
\hline Romiplostim & $\begin{array}{l}€ 602.50 / 250 \mu \mathrm{g} \\
\text { vial }\end{array}$ & $\begin{array}{c}3 \mu \mathrm{g} / \mathrm{kg}=1 \times 250 \mu \mathrm{g} \\
\text { vial weekly }{ }^{\mathrm{a}}[13]\end{array}$ & $\begin{array}{c}4\left(1^{\text {st }} 8 \text { weeks }\right) \\
1 \text { (>8 weeks })\end{array}$ & 4 & - & $\begin{array}{r}€ 2,967.42\left(1^{\text {st }} 8 \text { weeks }\right) \\
€ 2,485.62 \text { (>8 weeks) }\end{array}$ \\
\hline Eltrombopag & $\begin{array}{l}€ 2,043.58 \\
\quad(28 \times 50 \mathrm{mg})[72]\end{array}$ & 55 mg/day [11] & $\begin{array}{c}4\left(^{\text {st }} 8 \text { weeks }\right) \\
1 \text { (>8 weeks })\end{array}$ & - & - & $\begin{array}{l}€ 2,865\left(1^{\text {st }} 8 \text { weeks }\right) \\
€ 2,380 \text { (>8 weeks) }\end{array}$ \\
\hline Rituximab & $\begin{array}{l}€ 277.58 \\
\quad(100 \mathrm{mg})\end{array}$ & $\begin{array}{l}1 \text { course } \\
\quad 4 \times 375 \mathrm{mg} / \mathrm{m}^{2}\end{array}$ & $\begin{array}{c}4\left(^{\text {st }} 8 \text { weeks }\right) \\
1 \text { (>8 weeks })\end{array}$ & - & 4 & $€ 9,896$ \\
\hline Azathioprine & $€ 36.75(56 \times 50 \mathrm{mg})$ & $2 \mathrm{mg} / \mathrm{kg} /$ day & 2 & - & - & $€ 377$ \\
\hline Mycophenolatemofetil & $\begin{array}{l}€ 164.84 \\
\quad(50 \times 500 \mathrm{mg})\end{array}$ & $2 \mathrm{~g} /$ day & 2 & - & - & $€ 714$ \\
\hline Cyclosporine & $\begin{array}{l}€ 151.11 \\
\quad(30 \times 100 \mathrm{mg})\end{array}$ & $3 \mathrm{mg} / \mathrm{kg} /$ day & 2 & - & - & $€ 682$ \\
\hline \multicolumn{7}{|l|}{ Rescue medications } \\
\hline IVIg & $€ 45 / g$ [17] & $1 \mathrm{~g} / \mathrm{kg}$ for 2 days & & & 2 & $€ 7,776$ \\
\hline IV methylprednisolone & $€ 0.15 / \mathrm{mg}$ & $4 \times 40 \mathrm{mg}$ & & & 4 & $€ 1,224$ \\
\hline \multicolumn{7}{|c|}{ Hospitalization costs [68] } \\
\hline $\begin{array}{l}\text { Intracranial } \\
\text { haemorrhage }\end{array}$ & & & & & & $€ 6,854$ \\
\hline GI bleed (inpatient) & & & & & & $€ 2,913$ \\
\hline Other inpatient bleed & & & & & & $€ 2,913$ \\
\hline Outpatient bleed & & & & & & $€ 149$ \\
\hline
\end{tabular}

${ }^{a}$ Cost of full $250-\mu \mathrm{g}$ vial was included in the analysis

GI gastrointestinal, IV intravenous, IVIg intravenous immunoglobin 
of $€ 70.01$ per $\mathrm{g}$ (based on a weighted average of the different available pack sizes) [27]. Uncertainty around the price of IVIg was tested within the model (€37.60-52.40). Although $70 \%$ of patients self-administered romiplostim in the open-label extension study [15], self-administration was not included in the model.

\subsection{Model Outputs}

For each of the three treatments (i.e. romiplostim, eltrombopag and $\mathrm{SoC}$ ), the model calculated the following over the patient's lifetime:

- average number of administrations of rescue medication (IVIg or intravenous steroids);

- average number of bleeds;

- average number of hospitalizations.

Corresponding total costs, quality-adjusted life-years (QALYs) and life-years (LYs) per patient, and the incremental cost-effectiveness ratio (ICER) for romiplostim, were calculated.

\subsubsection{Sensitivity Analysis}

Scenario analyses were conducted to test alternative scenarios in the model, addressing structural uncertainty. These included the following:

- treatment duration of TPOra for 1 year instead of lifelong;

- placing TPOra after rituximab in the treatment pathway;

- response rate of eltrombopag (impact of using the unadjusted response rate taken directly from the clinical trial vs. the adjusted response rate taken from the indirect comparison);

- use of the EQ-5D as a source for utilities.

Deterministic sensitivity analysis was performed to identify the parameters to which the model was most sensitive, within their upper and lower bounds as defined by $95 \%$ confidence intervals where possible, or with plausible variation around the base-case values. The deterministic sensitivity analysis was based on incremental net benefit, which was calculated as the incremental QALYs multiplied by the willingness-to-pay threshold, minus incremental costs. Probabilistic sensitivity analysis (PSA) was conducted using 1,000 iterations to examine parameter uncertainty over the entire model. The following parameters were included in sensitivity analyses: response rates, durations, bleeding and rescue medication use, utilities, the proportion of patients using each SoC treatment, drug, resource use and bleed costs, and patient demographics (Table 3A, Online Resource 1).

\section{Results}

\subsection{Base Case}

The base-case (lifetime time horizon) model results (Table 4) indicated that romiplostim treatment resulted in an average of 20.2 fewer administrations of rescue medication (IVIg or intravenous steroids) over a patient lifetime than eltrombopag and 29.3 fewer administrations than SoC. The mean cost saving resulting from the reduction in rescue medications associated with romiplostim was $€ 148,118$ when compared with eltrombopag and $€ 214,565$ when compared with SoC. Additionally, romiplostim was associated with an average of 6.7 fewer bleeds and 1.7 fewer hospitalizations than eltrombopag and 8.7 fewer bleeds and 2.4 fewer hospitalizations than SoC. The mean cost saving resulting from the reduction in bleeds (including hospitalizations) was, on average, $€ 6,888$ when compared with eltrombopag and $€ 10,296$ when compared with SoC.

In total, the introduction of romiplostim into the beginning of the current treatment sequence resulted, on average, in a cost saving of $€ 13,258$ versus eltrombopag and $€ 22,673$ versus SoC and was also associated with a QALY gain of 0.76 versus eltrombopag and 1.17 versus SoC. Romiplostim was therefore the dominant treatment, i.e. more effective at a lower cost, and associated with cost savings and QALY gains versus both eltrombopag and SoC.

\subsection{Scenario Analyses}

Several scenario analyses were conducted (Table 5). In the short-term (1 year) TPOra treatment scenario, romiplostim was associated with an average cost saving of $€ 335$ and a QALY gain of 0.10 versus eltrombopag; hence, the use of romiplostim remained dominant. When compared with SoC, romiplostim was, on average, associated with an additional cost of $€ 895$ and a QALY gain of 0.22 . This resulted in an ICER of $€ 4,155$, indicating that the use of romiplostim remained cost effective.

The use of romiplostim after rituximab resulted in similar cost savings and QALY gains compared with both SoC and eltrombopag, the average cost saving increasing to $€ 16,279$ and $€ 27,022$ compared with eltrombopag and $\mathrm{SoC}$, respectively.

Additional scenario analysis tested the effect of using the response rate of eltrombopag derived from the eltrombopag clinical trial (instead of the response rate from the Bayesian meta regression of romiplostim and eltrombopag) [18]. Romiplostim remained dominant over eltrombopag, despite using a higher eltrombopag response rate (57 vs. $35 \%$ ) [Table 5].

Using the EQ-5D utility values resulted in a dominant ICER for romiplostim compared with both eltrombopag and SoC (Table 5). 
Table 4 Base-case cost effectiveness of romiplostim compared with eltrombopag and standard of care

\begin{tabular}{llll}
\hline & Romiplostim & Eltrombopag & SoC \\
\hline Cost of rescue therapy & $€ 365,485$ & $€ 537,617$ & $€ 580,050$ \\
Cost of bleeds & $€ 17,126$ & $€ 24,617$ & $€ 27,422$ \\
Other costs ${ }^{\mathrm{a}}$ & $€ 216,092$ & $€ 74,345$ & $€ 13,904$ \\
Total costs & $€ 598,704$ & $€ 611,962$ & $€ 621,376$ \\
LY gained & 14.70 & 13.97 & 13.57 \\
QALYs gained & 12.08 & 11.32 & 10.91 \\
\hline & & Romiplostim vs eltrombopag & Romiplostim vs SoC \\
\hline Incremental total costs & - & $-€ 13,258$ & $-€ 22,673$ \\
LYs gained & - & 0.73 & 1.13 \\
QALYs gained & - & 0.76 & 1.17 \\
ICER & - & Dominant & Dominant \\
\hline
\end{tabular}

The figures used in the model include all relevant decimal places. The figures shown in this table are rounded and as a result, any calculations made solely using the rounded figures may not provide an accurate result

${ }^{a}$ Other costs are active treatment costs: drug, physician and other utilization costs, and account for the length of time on therapy

ICER incremental cost-effectiveness ratio, $L Y$ life-year, $Q A L Y$ quality-adjusted life-year, SoC standard of care, Dominant indicates more effective at lower cost

\subsection{Deterministic and Probabilistic Sensitivity Analyses}

Figure 3 shows the results of the deterministic sensitivity analysis, presented as the incremental net benefit considering a willingness-to-pay threshold of $€ 30,000$ per QALY. The variables with the largest effect on the model were similar when comparing romiplostim with either eltrombopag or SoC. These were use of romiplostim, and the cost and use of IVIg. It should be noted that these findings are driven by the chosen ranges used in sensitivity analyses. No variables had an impact on the cost-effectiveness results at a threshold of $€ 30,000$ per QALY.

PSA showed that, in the majority of cases, treatment with romiplostim was more cost effective than treatment with either eltrombopag or SoC (Fig. 4). Romiplostim dominated both eltrombopag and SoC in over $66 \%$ of cases, with a mean incremental net benefit of $€ 35,823$

Table 5 Sensitivity analyses

\begin{tabular}{|c|c|c|c|c|c|}
\hline Treatment arm & Costs $(€)$ & QALYs & Incremental costs $(€)$ & Incremental QALYs & ICER \\
\hline \multicolumn{6}{|c|}{ Short-term treatment duration with TPOra ( 1 year) } \\
\hline SoC & 621,376 & 10.91 & - & - & \\
\hline Romiplostim & 622,272 & 11.13 & 895 & 0.22 & $€ 4,155$ \\
\hline Eltrombopag & 622,607 & 11.03 & 335 & -0.10 & Dominated \\
\hline \multicolumn{6}{|c|}{ Use of TPOra after rituximab treatment } \\
\hline Romiplostim & 594,354 & 12.05 & - & - & - \\
\hline Eltrombopag & 610,633 & 11.31 & 16,279 & -0.74 & Dominated \\
\hline $\mathrm{SoC}$ & 621,376 & 10.91 & 10,743 & -0.40 & Dominated \\
\hline \multicolumn{6}{|c|}{ Use of unadjusted response rate for eltrombopag } \\
\hline Romiplostim & 598,704 & 12.08 & - & - & - \\
\hline Eltrombopag & 604,209 & 11.55 & 5,506 & -0.54 & Dominated \\
\hline $\mathrm{SoC}$ & 621,376 & 10.91 & 17,167 & -0.63 & Dominated \\
\hline \multicolumn{6}{|c|}{ Use of EQ-5D utility values } \\
\hline Romiplostim & 598,704 & 11.29 & - & - & - \\
\hline Eltrombopag & 611,962 & 10.61 & 13,258 & -0.68 & Dominated \\
\hline SoC & 621,376 & 10.24 & 9,415 & -0.37 & Dominated \\
\hline
\end{tabular}

The figures used in the model include all relevant decimal places. The figures shown in this table are rounded and as a result, any calculations made solely using the rounded figures may not provide an accurate result

ICER incremental cost-effectiveness ratio, QALY quality-adjusted life-year, SoC standard of care, TPOra thrombopoietin receptor agonist, Dominated indicates less effective at higher cost 
(a)

Parameter: mean $(95 \% \mathrm{Cl}$ or plausible range)

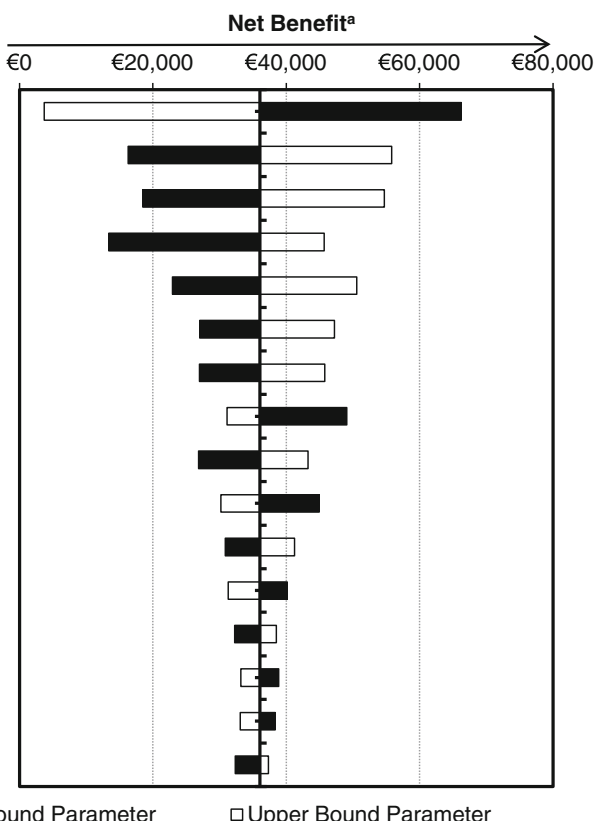

(b)

Romiplostim usage: 1 (0.84-1.17) vials/week

IVIg cost: $€ 45(37.60-52.40) / g$

IVIg usage for patients with platelets $\geq 50 \times 10^{9} / \mathrm{L}: 0.4$ (0.33-0.47) rate/cycle Utility for platelets $\geq 50 \times 10^{9} / \mathrm{L}$ and no bleed: 0.863 (0.54-0.999)

Romiplostim response duration: 140.86 (96.76-211.02) cycles

IV steroid use for patients with platelets $<50 \times 10^{9} / \mathrm{L}$ : $0.08(0.05-0.13)$ rate/cycle

Eltrombopag cost: €2043.58 (1719.45-2390.93)/pack

Utility for platelets $<50 \times 10^{9} / \mathrm{L}$ and no bleed: $0.84(0.42-1)$

Romiplostim response rate: 83 (70-93)\% patients

Utility for platelets $<50 \times 10 \% / L$ and OP bleed: 0.73 (0.37-0.97)

IVIg daily admin cost: $€ 300$ (145.05-454.95)

Eltrombopag response duration: 89.66 (69.86-116.72) cycles

Utility for platelets $\geq 50 \times 10^{9} / \mathrm{L}$ and OP bleed: $0.73(0.37-0.97)$

Eltrombopag response rate: $35(31-40) \%$ patients

Probability of inpatient bleed if platelets $<50 \times 10 \% / L: 4(1-7) \%$ patients

- Lower Bound Parameter

¿Upper Bound Parameter

Parameter: mean (95\% $\mathrm{Cl}$ or plausible range)

Romiplostim usage: 1 (0.84-1.17) vials/week

IVIg cost: $€ 45(37.60-52.40) / g$

IVIg usage for patients with platelets $<50 \times 10 \% / \mathrm{L}: 0.4(0.33-0.47)$ rate/cycle

Utility for platelets $\geq 50 \times 10 \% / L$ and no bleed: $0.86(0.54-1)$

IV steroid use for patients with platelets $<50 \times 10^{9} / \mathrm{L}$ : $0.08(0.05-0.13)$ rate/cycle

Romiplostim response duration: 140.86 (96.76-211.02) cycles

Utility for platelets $<50 \times 10^{9} / \mathrm{L}$ and no bleed: $0.841(0.42-1)$

Utility for platelets $<50 \times 10^{9} / \mathrm{L}$ and OP bleed: $0.732(0.37-0.97)$

Romiplostim response rate: 83 (70-93) \% patients

IVIg daily admin cost: $€ 300(145.05-454.95)$

Utility for platelets $\geq 50 \times 10 \% / \mathrm{L}$ and OP bleed: $0.734(0.37-0.97)$

Probability of inpatient bleed if platelets $<50 \times 10^{9} / \mathrm{L}: 4(1-7) \%$ patients

Azathioprine response duration: 20.34 (41.07- 3.52) cycles

IV steroids admin cost: $€ 300$ (145.05-454.95)/day

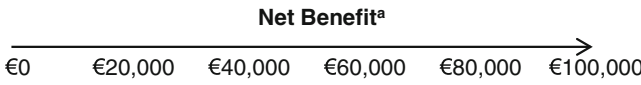

Fig. 3 Deterministic sensitivity analysis: a romiplostim vs. eltrombopag, b romiplostim vs. standard of care (incremental net benefit is based on the incremental QALYs multiplied by the willingness-to-pay

versus eltrombopag and $€ 56,869$ versus $\mathrm{SoC}$ at a $€ 30,000$ per QALY threshold (Figure 2A, Online Resource 1). There was a $90 \%$ probability that romiplostim was cost effective versus eltrombopag and a $96 \%$ probability versus SoC at a threshold of $€ 30,000$ per QALY (Figure 2A, Online Resource 1).
- Lower Bound Parameter

threshold, minus incremental costs. The central vertical line represents the base-case net benefit). $C I$ confidence interval, $I V$ intravenous, IVIg intravenous immunoglobulin, $O P$ outpatient

\section{Discussion}

In phase III randomized, placebo-controlled clinical trials, the majority of patients treated with romiplostim achieved a platelet count of $\geq 50 \times 10^{9} / \mathrm{L}$, while bleeding events and the need for concurrent ITP therapies, including 
Fig. 4 Cost-effectiveness romiplostim, eltrombopag and standard of care. $Q A L Y$ quality-adjusted life-year acceptability frontier for

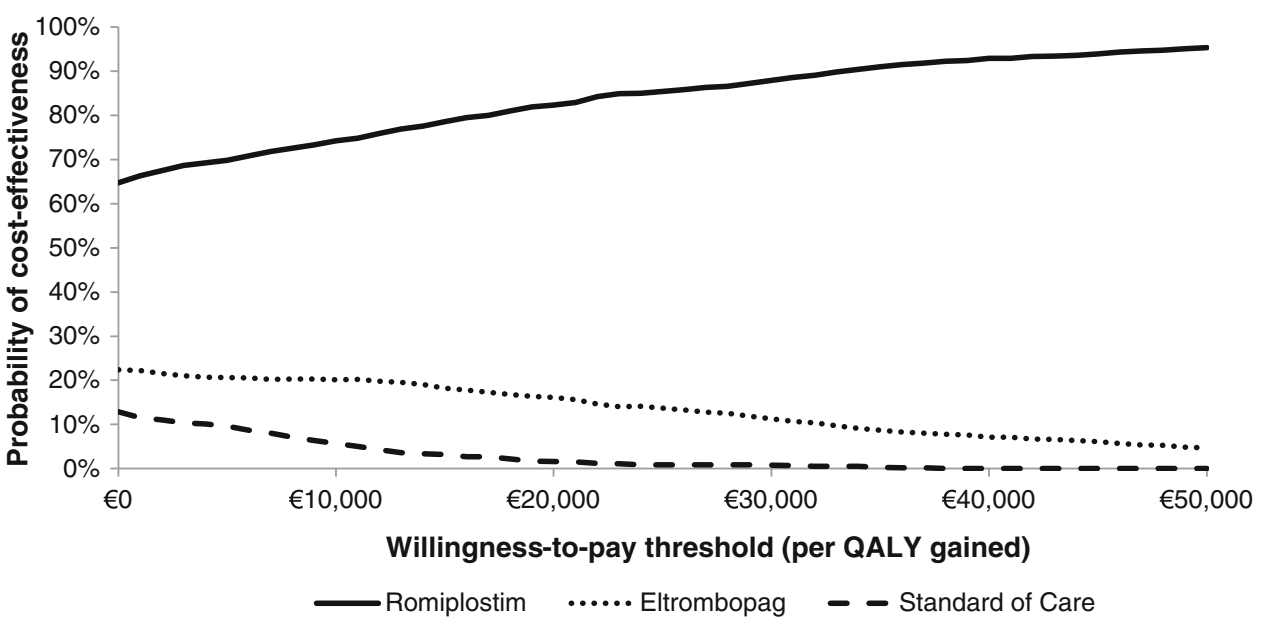

corticosteroids and rescue treatments, were reduced [13, 21, 28-30]. Long-term extension studies demonstrated that platelet responses were sustained during prolonged treatment periods of up to 5 years $[15,31,32]$, with use of glucocorticoids continuing to decrease [29]. The efficacy of romiplostim was also demonstrated in a European observational study [26].

The model presented here showed that romiplostim treatment was dominant, demonstrating better efficacy and cost savings than both eltrombopag and SoC. Savings were achieved through the higher response rates associated with romiplostim, which led to a reduction in bleeding-related episodes, including the use of rescue therapies. Romiplostim remained dominant throughout a variety of potential scenarios, including short-term (1 year) treatment with TPOra, placement after rituximab, use of unadjusted response rates for eltrombopag and the use of an alternative source for utility values. The model was most sensitive to assumptions surrounding the use of romiplostim, IVIg and steroids, and the duration of response to romiplostim. Nevertheless, romiplostim remained cost effective for all model parameters. PSA showed that romiplostim was likely to be cost effective in over $90 \%$ of cases versus eltrombopag and $96 \%$ versus SoC at a willingness-to-pay threshold of $€ 30,000$ per QALY.

The results of this cost-effectiveness analysis were dependent on Irish treatment practice and the healthcare system. Although the driver of the cost-effectiveness results was the efficacy of romiplostim, transferability of the results to other countries is subject to local costing and healthcare systems. Romiplostim has been shown to be cost effective compared with SoC and rituximab in other countries. In Canada, a net cost impact model showed that romiplostim is less expensive to prepare and administer than IVIg and is associated with lower indirect costs from a Canadian healthcare perspective [33]. Romiplostim was also associated with lower cost per response over 6 months when compared with rituximab from the French national health system perspective [34] and when compared with SoC in Spain [35].

Although the results of our analysis were robust to multiple sensitivity analyses, several limitations need to be recognized. Direct comparison could not be made between romiplostim and eltrombopag due to a lack of head-to-head clinical trial data. Hence, estimates of comparative efficacy between the treatments were made using the indirect comparison recommended by Cooper et al. [18]. Uncertainty in this indirect comparison was assessed both in PSA and through scenario analysis. When the unadjusted response rates were used for both TPOra, romiplostim still provided better efficacy over eltrombopag, and remained cost saving. Additionally, clinical trial data for romiplostim and eltrombopag were comparatively better quality, and more recent, than the data for the other treatments (notably rituximab). Moreover, in some cases, published data for treatment pathways in Ireland were not available. Where this was the case, clinician validation by two Irish clinicians was used. Data from the USA have been used in estimating the mortality associated with ITP, as information was not available for Ireland or the UK. However, the impact of this parameter is limited, as one-way sensitivity analysis showed that it was not a key model driver.

The model was built from the perspective of the national healthcare payer in Ireland. The exclusion of a wider societal perspective could have underestimated overall costs associated with treatment. For romiplostim, because of more frequent nurse appointments associated with subcutaneous administration, indirect costs could include costs for time taken off work, transport and other out-of-pocket costs. However, the magnitude of these additional costs is uncertain, especially as a large proportion of romiplostim patients are able to administer romiplostim at home [15]. A lifetime time horizon was deemed to be the most appropriate, since adult ITP tends to be a chronic disease; the 
4-week cycle was used to match the evaluation schedule used in the long-term romiplostim extension study [15].

The base-case analyses assumed that TPOra were placed before rituximab in the treatment pathway and used according to their approved indication in Europe, i.e. adult patients with chronic ITP failing splenectomy or as secondline therapy in patients who have contraindications to surgery $[10,11]$. We assumed that patients would receive, successively, azathioprine, mycophenolate mofetil and cyclosporine, after TPOra and rituximab. We did not include splenectomy in the model since it was assumed that all patients who were candidates for this procedure would already have been splenectomized.

It is important to note that the model was based on conservative assumptions. We assumed that only one course of rituximab was given, whereas the literature suggests that repeated courses may be needed to sustain response [2, 36]. The lack of inclusion of adverse events also represents a conservative assumption when comparing romiplostim with SoC. Available data indicate that romiplostim has a good safety profile [37], particularly in comparison with currently available treatments that are based on immunosuppression, which may predispose patients to serious infections, a major cause of death in ITP patients [38]. However, the exclusion of adverse effects associated with romiplostim and other treatments may underestimate the overall treatment costs reported in this analysis.

\section{Conclusions}

In summary, the addition of romiplostim to the chronic ITP treatment pathway, compared with eltrombopag or SoC including rituximab, is likely to be cost effective in Ireland. This was shown despite the generally conservative assumptions applied in the model.

\section{Acknowledgments Amgen (Europe) $\mathrm{GmbH}$ provided financial support for development of the model and manuscript. Julia Balfour, medical writer, Dundee, UK, provided editorial, formatting and ref- erencing support.}

Author contributions DL, AH, PT and LK evaluated the literature. $\mathrm{DL}, \mathrm{AH}, \mathrm{LK}, \mathrm{RD}$ and NB were involved in the model design. DL, AH and NB built the model and conducted the model analyses. PT provided input on Irish clinical practice. DL, LK, NB and PT interpreted the data. DL, PT, LK and AH drafted the manuscript. All authors reviewed and approved the final submitted version of the manuscript. $\mathrm{DL}$ is the guarantor for the overall content.

Conflicts of interest $\mathrm{LK}$ is an employee, and $\mathrm{RD}$ a former employee, of Amgen, and both hold stock options in the company. DL, AH and NB are employees of BresMed Health Solutions Ltd, a consulting company contracted by Amgen to develop the costeffectiveness model. PT has no conflicts of interest to declare.
Open Access This article is distributed under the terms of the Creative Commons Attribution Noncommercial License which permits any noncommercial use, distribution, and reproduction in any medium, provided the original author(s) and the source are credited.

\section{References}

1. Rodeghiero F, Stasi R, Gernsheimer T, Michel M, Provan D, Arnold DM, et al. Standardization of terminology, definitions and outcome criteria in immune thrombocytopenic purpura (ITP) of adults and children: report from an International Working Group. Blood. 2009;113:2386-93.

2. Provan D, Stasi R, Newland AC, Blanchette VS, Bolton-Maggs $\mathrm{P}$, Bussel JB, et al. International consensus report on the investigation and management of primary immune thrombocytopenia. Blood. 2010;115(2):168-86.

3. Terrell DR, Beebe LA, Vesely SK, Neas BR, Segal JB, George JN. The incidence of immune thrombocytopenic purpura in children and adults: a critical review of published reports. Am J Hematol. 2010;85(3):174-80.

4. Marieke Schoonen W, Kucera G, Coalson J, Li L, Rutstein M, Mowat $\mathrm{F}$, et al. Epidemiology of immune thrombocytopenic purpura in the General Practice Research Database. Br J Haematol. 2009;145(2):235-44.

5. McMillan R, Bussel JB, George JN, Lalla D, Nichol JL. Selfreported health-related quality of life in adults with chronic immune thrombocytopenic purpura. Am J Hematol. 2008;83(2): $150-4$.

6. Khellaf M, Le Moine JG, Poitrinal P, Francesconi C, Haddad A, Bierling $\mathrm{P}$, et al. Costs of managing severe immune thrombocytopenia in adults: a retrospective analysis. Ann Hematol. 2011;90(4):441-6.

7. Tarantino MD, Mathias SD, Snyder CF, Isitt JJ, Gernsheimer T, Young J. Impact of ITP on physician visits and workplace productivity. Curr Med Res Opin. 2010;26(2):319-28.

8. Aledort LM, Lyons RM, Okano G, Leveque J. The clinical and direct medical cost burden of splenectomy among managed care patients with chronic immune thrombocytopenic purpura (ITP). ASH Annual Meeting Abstracts. 2006;108(11):5536.

9. Danese MD, Lindquist K, Gleeson M, Deuson R, Mikhael J. Cost and mortality associated with hospitalizations in patients with immune thrombocytopenic purpura. Am J Hematol. 2009;84(10): $631-5$.

10. Amgen B.V. Nplate ${ }^{\circledR}$ summary of product characteristics. http://www.ema.europa.eu/docs/en_GB/document_library/EPAR_Product_Information/human/000942/WC500039537.pdf(Accessed 11 May 2013).

11. GlaxoSmithKline. Revolade summary of product characteristics. http://www.ema.europa.eu/docs/en_GB/document_library/EPAR_-Product_Information/human/001110/WC500089964.pdf(Accessed 25 Oct 2011).

12. Health Information and Quality Authority (HIQA). Guidelines for the economic evaluation of health technologies in Ireland (Appendix 4); 2010. http://www.hiqa.ie/publication/guidelineseconomic-evaluation-health-technologies-ireland (Accessed 8 July 2012).

13. Kuter DJ, Bussel JB, Lyons RM, Pullarkat V, Gernsheimer TB, Senecal FM, et al. Efficacy of romiplostim in patients with chronic immune thrombocytopenic purpura: a double-blind randomised controlled trial. Lancet. 2008;371(9610):395-403.

14. Harrington J, Perry IJ, Lutomski J, et al. SLAN 2007: survey of lifestyle, attitudes and nutrition in Ireland. Dietary habits of the 
Irish population, Department of Health and Children. Dublin: The Stationery Office; 2008.

15. Kuter DJ, Bussel JB, Newland A, Wasser JS, Lyons RM, George $\mathrm{JN}$, et al. Long-term efficacy and safety of romiplostim treatment of adult patients with chronic immune thrombocytopenia (ITP): final report from an open-label extension study (ASH Annual Meeting Abstracts). Blood. 2010;116(21):68.

16. Amgen (Europe) GmbH. Idiopathic thrombocytopenia purpura, Docscan \& Physician Connect Survey; 2008 (data on file).

17. O'Keeffe D. Midwestern Regional Hospital, Limerick, Ireland; Thornton, P, Beaumont Hospital, Ireland (Personal Communication), February 2012.

18. Cooper KL, Fitzgerald P, Dillingham K, Helme K, Akehurst R. Romiplostim and eltrombopag for immune thrombocytopenia: methods for indirect comparison. Int $\mathrm{J}$ Technol Assess Health Care. 2012;28(3):249-58.

19. Saleh MN, Cheng G, Bussel JB, Burgess P, Bakshi K, Brainsky A, et al. Long-term safety and efficacy of eltrombopag in adults with chronic immune thrombocytopenia (ITP): report of up to 5.5 years of treatment in EXTEND. Blood (ASH Annual Meeting Abstracts). 2012;120(21):2198.

20. Latimer N. National Institute for Health and Clinical Excellence, Decision Support Unit technical support document 14: survival analysis for economic evaluations alongside clinical trialsextrapolation with patient level data. 2011 (updated 2013). http://www.nicedsu.org.uk (Accessed 13 May 2013).

21. Weitz I, Sanz MA, Henry D, Schipperus M, Godeau B, Northridge $\mathrm{K}$, et al. A novel approach to the evaluation of bleedingrelated episodes in patients with chronic immune thrombocytopenia. Curr Med Res Opin. 2012;28(5):789-96.

22. Anon. Irish life table no. 15, 2005-2007. Central Statistics Office, Ireland. http://www.cso.ie/en/newsandevents/pressreleases/2009 pressreleases/irishlifetableno152005-2007/ (Accessed 11 Dec 2012).

23. Szende A, Brazier J, Schaefer C, Deuson R, Isitt JJ, Vyas P. Measurement of utility values in the UK for health states related to immune thrombocytopenic purpura. Curr Med Res Opin. 2010;26(8):1893-903.

24. McNamara RL, Lima JA, Whelton PK, Powe NR. Echocardiographic identification of cardiovascular sources of emboli to guide clinical management of stroke: a cost-effectiveness analysis. Ann Int Med. 1997;127(9):775-87.

25. Sanz MA, Aledort L, Mathias SD, Wang X, Isitt JJ. Analysis of EQ-5D scores from two phase 3 clinical trials of romiplostim in the treatment of immune thrombocytopenia (ITP). Value Health. 2011;14(1):90-6.

26. Wadenvik H, Steurer M, Janssens A, et al. Romiplostim for the treatment of adults with primary immune thrombocytopenia (ITP) in routine clinical practice-interim results from a large, European, observational study [abstract no. 0611]. Haematologica. 2011;97(S1):252.

27. Anon. Monthly Index of Medical Specialities (December). Haymarket Group; 2011.

28. Shirasugi Y, Ando K, Miyazaki K, Tomiyama Y, Okamoto S, Kurokawa M, et al. Romiplostim for the treatment of chronic immune thrombocytopenia in adult Japanese patients: a double-blind, randomized phase III clinical trial. Int J Hematol. 2011;94(1):71-80.

29. Michel M, te Boekhorst PA, Janssens A, Pabinger-Fasching I, Sanz MA, Nie K, et al. Reduced corticosteroid use in adult patients with primary immune thrombocytopenia receiving romiplostim. Hematology. 2011;16(5):274-7.

30. Pullarkat VA, Gernsheimer TB, Wasser JS, Newland A, Guthrie TH Jr, de Wolf JT, et al. Quantifying the reduction in immunoglobulin use over time in patients with chronic immune thrombocytopenic purpura receiving romiplostim (AMG 531). Am J Hematol. 2009;84(8):538-40.
31. Bussel JB, Kuter DJ, Pullarkat V, Lyons RM, Guo M, Nichol JL. Safety and efficacy of long-term treatment with romiplostim in thrombocytopenic patients with chronic ITP. Blood. 2009;113(10): 2161-71 (Erratum in: Blood. 2009;113:4822).

32. Miyazaki K, Shirasugi Y, Ando K, Tomiyama Y, Iwato K, Okamoto S, Kurokawa M, Kirito K, Hashino S, Ninomiya H, Mori S, Yonemura Y, Usuki K, Wei H, Lizambri R. An openlabel extension study evaluating the safety and efficacy of up to 3.5 years of romiplostim in thrombocytopenic Japanese patients with chronic immune thrombocytopenic purpura (ITP). Haematologica. 2011;96(s2):229.

33. Pettigrew M, Garces K, Deuson R, Kassis J, Laroche V. Comparative net cost impact of the utilization of romiplostim and intravenous immunoglobulin for the treatment of patients with immune thrombocytopenia in Quebec, Canada. J Med Econ. 2013;16(2):318-26.

34. Chiche L, Lefrere F, Chulikavit M, et al. Cost-consequence analysis comparing romiplostim to rituximab in the treatment of adult primary immune thrombocytopenia (ITP) in France. Value Health. 2011;14(7):A415.

35. Brosa M, Arocho R, Gutierrez L, et al. A pharmacoeconomic evaluation of romiplostim (NPLATE) for the treatment of chronic immune thrombocytopenia (ITP) (Abstract PSY425). Value Health. 2010;13(7):A464.

36. Brah S, Chiche L, Fanciullino R, Bornet C, Mancini J, Schleinitz $\mathrm{N}$, et al. Efficacy of rituximab in immune thrombocytopenic purpura: a retrospective survey. Ann Hematol. 2012;91(2): 279-85.

37. Lam MS. Review article: second-generation thrombopoietin agents for treatment of chronic idiopathic thrombocytopenic purpura in adults. J Oncol Pharm Pract. 2010;16(2):89-103.

38. Portielje JE, Westendorp RG, Kluin-Nelemans HC, Brand A. Morbidity and mortality in adults with idiopathic thrombocytopenic purpura. Blood. 2001;97(9):2549-54.

39. Arnold DM, Dentali F, Crowther MA, Meyer RM, Cook RJ, Sigouin C, et al. Systematic review: efficacy and safety of rituximab for adults with idiopathic thrombocytopenic purpura. Ann Intern Med. 2007;146(1):25-33.

40. Zhou Z, Yang R. Rituximab treatment for chronic refractory idiopathic thrombocytopenic purpura. Crit Rev Oncol Hematol. 2008;65(1):21-31.

41. Cooper N, Stasi R, Cunningham-Rundles S, Feuerstein MA, Leonard JP, Amadori S, et al. The efficacy and safety of B-cell depletion with anti-CD20 monoclonal antibody in adults with chronic immune thrombocytopenic purpura. $\mathrm{Br} \mathrm{J}$ Haematol. 2004;125(2):232-9.

42. Godeau B, Porcher R, Fain O, Lefrere F, Fenaux P, Cheze S, et al. Rituximab efficacy and safety in adult splenectomy candidates with chronic immune thrombocytopenic purpura: results of a prospective multicenter phase 2 study. Blood. 2008;112(4): 999-1004.

43. Zaja F, Battista ML, Pirrotta MT, Palmieri S, Montagna M, Vianelli $\mathrm{N}$, et al. Lower dose rituximab is active in adults patients with idiopathic thrombocytopenic purpura. Haematologica. 2008;93(6):930-3.

44. Vianelli N, Valdre L, Fiacchini M, de Vivo A, Gugliotta L, Catani L, et al. Long-term follow-up of idiopathic thrombocytopenic purpura in 310 patients. Haematologica. 2001;86(5):504-9.

45. Vesely SK, Perdue JJ, Rizvi MA, Terrell DR, George JN. Management of adult patients with persistent idiopathic thrombocytopenic purpura following splenectomy: a systematic review. Ann Int Med. 2004;140(2):112-20.

46. Bouroncle BA, Doan CA. Treatment of refractory idiopathic thrombocytopenic purpura. JAMA. 1969;207(11):2049-52.

47. Quiquandon I, Fenaux P, Caulier MT, Pagniez D, Huart JJ, Bauters F. Re-evaluation of the role of azathioprine in the 
treatment of adult chronic idiopathic thrombocytopenic purpura: a report on 53 cases. Br J Haematol. 1990;74(2):223-8.

48. Kotb R, Pinganaud C, Trichet C, Lambotte O, Dreyfus M, Delfraissy JF, et al. Efficacy of mycophenolate mofetil in adult refractory auto-immune cytopenias: a single center preliminary study. Eur J Haematol. 2005;75(1):60-4.

49. Hou M, Peng J, Shi Y, Zhang C, Qin P, Zhao C, et al. Mycophenolate mofetil (MMF) for the treatment of steroid-resistant idiopathic thrombocytopenic purpura. Eur J Haematol. 2003;70(6):353-7.

50. Provan D, Moss AJ, Newland AC, Bussel JB. Efficacy of mycophenolate mofetil as single-agent therapy for refractory immune thrombocytopenic purpura. Am J Hematol. 2006;81(1):19-25.

51. Zver S, Zupan IP, Cernelc P. Cyclosporin A as an immunosuppressive treatment modality for patients with refractory autoimmune thrombocytopenic purpura after splenectomy failure. Int $\mathbf{J}$ Hematol. 2006;83(3):238-42.

52. Peng J, Liu C, Liu D, Ren C, Li W, Wang Z, et al. Effects of B7blocking agent and/or CsA on induction of platelet-specific T-cell anergy in chronic autoimmune thrombocytopenic purpura. Blood. 2003;101(7):2721-6.

53. Kappers-Klunne MC, van't Veer MB. Cyclosporin A for the treatment of patients with chronic idiopathic thrombocytopenic purpura refractory to corticosteroids or splenectomy. Br J Haematol. 2001;114(1):121-5.

54. Robak T, Salama A, Kovaleva L, Vyhovska YI, Davies S, Mazzucconi MG, et al. Efficacy and safety of a new intravenous immunoglobulin product in patients with chronic immune thrombocytopenic purpura. ASH Annual Meeting Abstracts. 2007;110(11):1307.

55. Julia A, Kovaleva L, Alberca I, Hernandez F, Loria S, Sandoval $\mathrm{V}$, et al. Study on the efficacy and safety of IGIV3I Grifols (human intravenous immunoglobulin) in patients diagnosed with chronic immune thrombocytopenic purpura. ASH Annual Meeting Abstracts. 2006;108(11):3956.

56. Milligan D, Eden A, Sklenar I, Adams C, Andresen I, Bender K. Therapy of patients with chronic immune thrombocytopenic purpura (ITP): efficacy, tolerability, and safety of a new liquid intravenous immunoglobulin (Abstract 485). Hematol J. 2004;5 (suppl.):S168.

57. Unsal C, Gürkan E, Güvenç B, et al. Anti-D and intravenous immunoglobulin treatments in chronic idiopathic thrombocytopenic purpura. Turkish J Haematol. 2004;21(1):27-32.

58. Bussel JB, Eldor A, Kelton JG, Varon D, Brenner B, Gillis S, et al. IGIV-C, a novel intravenous immunoglobulin: evaluation of safety, efficacy, mechanisms of action, and impact on quality of life. Thromb Haemost. 2004;91(4):771-8.

59. Wolf HH, Davies SV, Borte M, Caulier MT, Williams PE, Bernuth HV, et al. Efficacy, tolerability, safety and pharmacokinetics of a nanofiltered intravenous immunoglobulin: studies in patients with immune thrombocytopenic purpura and primary immunodeficiencies. Vox Sang. 2003;84(1):45-53.

60. Colovic M, Dimitrijevic M, Sonnenburg C, Suvajdzic N, Donfrid M, Bogdanovic A. Clinical efficacy and safety of a novel intravenous immunoglobulin preparation in adult chronic ITP. Hematol J. 2003;4(5):358-62.

61. Pugina SA, Evdokimova NM, Rastorguev GG, Samoilova OS, Sorokina IV, Sidnev GV, et al. Treatment of idiopathic thrombocytopenic purpura in adults: efficacy of domestic intravenous immunoglobulin in immune thrombocytopenia. Ter Arkh. 1999;71(8):50-4.

62. Altintop L, Albayrak D. Oral high-dose methylprednisolone and intravenous immunoglobulin treatments in adult chronic idiopathic thrombocytopenic purpura. Am J Hematol. 1997;56(3):191-2.

63. Jacobs P, Wood L, Novitzky N. Intravenous gammaglobulin has no advantages over oral corticosteroids as primary therapy for adults with immune thrombocytopenia: a prospective randomized clinical trial. Am J Med. 1994;97(1):55-9.

64. Godeau B, Lesage S, Divine M, Wirquin V, Farcet JP, Bierling P. Treatment of adult chronic autoimmune thrombocytopenic purpura with repeated high-dose intravenous immunoglobulin. Blood. 1993;82(5):1415-21.

65. Leibl H, Varga G, Volkova Z, Gasztonyi Z, Hlusi A, Mayer J, et al. Efficacy and safety of a new intravenous immunoglobulin in adult subjects with chronic idiopathic thrombocytopenic purpura. ASH Annual Meeting Abstracts. 2005;106(11):3984.

66. George JN, Woolf SH, Raskob GE, Wasser JS, Aledort LM, Ballem PJ, et al. Idiopathic thrombocytopenic purpura: a practice guideline developed by explicit methods for the American Society of Hematology. Blood. 1996;88(1):3-40.

67. Scaradavou A, Woo B, Woloski BM, Cunningham-Rundles S, Ettinger LJ, Aledort LM, et al. Intravenous anti-D treatment of immune thrombocytopenic purpura: experience in 272 patients. Blood. 1997;89(8):2689-700.

68. Casemix Ireland. Ready Reckoner 2011, National Casemix Program, Health Service Executive. http://www.casemix.ie (Accessed 20 Jan 2012).

69. Anon. Mater hospital cost, 2006. Inflated to November 2011 costs with the health inflator derived from central statistics office, Ireland.

70. National Health Service. National schedule of reference costs 2009-10 for NHS trusts. http://data.gov.uk/dataset/nhs-referencecosts-2009-10 (Accessed 2 Jan 2012).

71. National Centre for Pharmacoeconomics Ireland. Personal Communication; 2012.

72. National Centre for Pharmacoeconomics. Cost-effectiveness of eltrombopag (Revolade) for the treatment of chronic immune thrombocytopenic purpura (ITP). http://www.ncpe.ie/wp-content/ uploads/2012/03/Summary-for-Thrombocytopenic-purpura.pdf (Accessed 13 May 2013). 